\title{
THE PSYCHOBIOLOGY OF PREMENSTRUAL DYSPHORIA: THE ROLE OF PROLACTIN
}

\author{
Bernard J. Carroll and Meir Steiner \\ Mental Health Research Institute, Department of Psychiatry, University of Michigan, Ann Arbor, Michigan \\ 48109, U.S.A.
}

(Received 15 December 1976, revised 2 December 1977)

\begin{abstract}
SUMMARY
(1) The evidence for a role of prolactin in the premenstrual syndrome is discussed in this review. (2) The timing of the onset and offset of both physical and psychological dysphoric symptoms corresponds with the luteal elevation and menstrual decrease of serum prolactin levels. (3) Women with premenstrual symptoms have been shown to have high prolactin levels throughout the menstrual cycle and especially in the premenstruum. (4) Suppression of prolactin secretion with bromocriptine is reported to be effective in preventing both physical and psychological premenstrual symptoms. (5) The mode of action of bromocriptine requires further study to exclude possible direct central nervous system effects of the drug, independent of its prolactin-suppressing action. (6) Indirect evidence for a role of prolactin in the premenstrual syndrome comes from (a) the actions of prolactin in causing renal retention of water, sodium and potassium; (b) the interactions of prolactin with lithium (which is reported to relieve premenstrual symptoms in some patients); some of the other reported treatments also may suppress prolactin secretion or antagonize its peripheral effects. (7) Prolactin may interact with the ovarian hormones to cause specific types of dysphoric symptoms. High prolactin levels associated with low estrogen levels may cause depressive symptoms. High prolactin levels associated with low progesterone levels may cause symptoms of anxiety or irritable hostility. (8) Interactions of prolactin with the ovarian hormones may also help to account for some related clinical states-mid-cycle mood elevations, elation in late pregnancy, postpartum depression and dysphoric menopausal symptoms.
\end{abstract}

\section{INTRODUCTION}

IN A PRECEDING paper (Steiner \& Carroll, 1977) we reviewed the varied manifestations of the premenstrual syndrome, the many suggested theories concerning its etiology and the range of unsatisfactory treatments recommended for it. One way of integrating many of these observations with the physiology of the menstrual cycle is to propose that prolactin plays a major role in the premenstrual syndrome. This idea was first advanced by Horrobin (1973a) and recent findings have appeared which strongly support his theory. In this paper we shall review the several lines of evidence for a role of prolactin (PRL) in the premenstrual syndrome and possibly in other clinical states as well.

\section{Direct evidence}

1. The timing of the premenstrual symptoms coincides with the late luteal elevation of plasma PRL levels. The reported studies of PRL changes during the menstrual cycle were reviewed in the previous paper, and it was pointed out that some women have significantly 
higher PRL levels during this phase than during the follicular phase (Franchimont, Dourcy, Legros, Reuter, Vrindts-Gevaert, Van Cauwengerge \& Gaspard, 1976; Vekemans, Delvoye, L'Hermite \& Robyn, 1977). Furthermore, the elevated PRL levels do not drop until the onset of menstruation, which coincides with the relief of premenstrual symptoms. By contrast, the levels of renin, angiotensin II, aldosterone, estrogens and progesterone decrease several days earlier, at about the time the symptoms first appear.

2. Women with high premenstrual ratings of dysphoria have significantly elevated $P R L$ levels during the premenstruum (Guy E. Abraham, personal communication, 1976). This report has been documented further by Halbreich, Assael, Ben-David \& Borstein (1976). In their study, women with premenstrual symptoms were compared with women who reported no premenstrual difficulties. The symptomatic women had higher PRL levels than the control women at all phases of the cycle; they also had significantly greater proportionate increases of PRL levels during the premenstruum. The authors commented that the high PRL levels in the symptomatic women could be due to the "stress" of their symptoms, but other lines of evidence to be discussed below make this seem unlikely.

3. The treatment results obtained with bromocriptine (which suppresses PRL secretion) argue strongly for a major influence of PRL in the premenstrual syndrome (BenedekJaszmann \& Hearn-Sturtevant, 1976). These authors believe that they "may have found the key to the aetiology of this syndrome." When PRL secretion was suppressed by bromocriptine over $90 \%$ of their subjects obtained complete relief from premenstrual symptoms for up to 11 months. No other treatment has ever been claimed to approach this level of effectiveness. This study contained only a small double-blind crossover controlled investigation, together with two open investigations. A more extensive controlled clinical trial will be needed to confirm this report. The clinical features rated in the study were " 1 . Breast swelling, discomfort and pain with or without discharge from the nipples. 2. Abdominal discomfort and swelling. 3. Migraine. 4. Weight gain and edema. 5. Psychological disturbances including lability of mood, depression and tiredness".

One remarkable aspect of the results is that improvement was observed in all of these areas. While the beneficial effect of bromocriptine on the physical symptoms may be due to PRL suppression, the psychological benefit could possibly have resulted from direct actions of bromocriptine on the central nervous system. For example, bromocriptine, being a dopamine receptor agonist, is used to treat Parkinson's disease (Thorner, McNeilly, Hagan \& Besser, 1974; Cooke, Foley, Lenton, Preston, Millar, Jenkins, Obiekwe, McNeilly, Parsons \& Kennedy, 1976; Calne, Teychenne, Claveria, Eastman, Greenacre \& Petrie, 1974). Since other dopamine agonists and suppressors of PRL such as L-dopa and piribedil also have behavioral effects (Chase \& Shoulson, 1975), further strategies will need to be developed to distinguish the PRL-suppressive action of bromocriptine from its possible direct central behavioral effects in women treated for the premenstrual syndrome. An extensive single case study reported by Horrobin, Mtabaji, Kermali, Manku \& Nassar (1976) also suggests that bromocriptine is effective against both physical and behavioral premenstrual symptoms.

Bromocriptine is an amino acid ergot alkaloid which is known to be a specific agonist of dopaminergic receptors (Fuxe, Agnati, Hokfelt, Jonsson, Lidbrink, Ljungdahl, Lofstrom \& Ungerstedt, 1975). It suppresses human prolactin secretion not only in the post-partum 
period and in the galactorrhea syndromes but also throughout the menstrual cycle. It is also effective in preventing the nocturnal pulsatile release of prolactin (DelPozo, 1973). Other dopamine agonists which suppress prolactin secretion in man include L-dopa (Malarkey, Jacobs \& Daughaday, 1971), apomorphine (Martin, Lal, Tolis \& Friesen, 1974), dopamine itself (Massara, Camanni, Belforte \& Molinatti, 1976), piribedil (Chase \& Shoulson, 1975) and two other ergot derivatives, namely ergonovine (Shane \& Naftolin, 1974) and lergotrile (Lilly 83636) (Lemberger, Crabtree, Clemens, Dyke \& Woodburn, 1974). L-Dopa, apomorphine and dopamine have durations of action which are generally too short to make them clinically useful. The most promising agents at the clinical level for long-term suppression of prolactin secretion are bromocriptine, lergotrile and piribedil. So far, only bromocriptine has actually been used in patients with premenstrual syndromes. We should expect any one of these three agents to be effective however.

\section{Indirect evidence}

1. Water and electrolyte retention. We noted in the previous paper that premenstrual edema is frequently associated with premenstrual dysphoria. There is general agreement that women gain 1-2 kg weight premenstrually and lose it in a diuresis when menstruation occurs (Israel, 1967). Along with the water retention there is also retention of both sodium $(\mathrm{Na})$ and potassium $(\mathrm{K})$. The sodium retention predominates, however, so that urinary $\mathrm{Na} / \mathrm{K}$ ratios increase. A woman with very severe premenstrual edema was described by Horrobin (1973a). She had profound oliguria and sodium retention, together with less severe but marked potassium retention, and a premenstrual weight gain of $6-10 \mathrm{~kg}$. The association of both $\mathrm{K}$ and $\mathrm{Na}$ retention is remarkable, since the mineralocorticoids (desoxycorticosterone, aldosterone and corticosterone) characteristically promote $\mathrm{K}$ loss in exchange for $\mathrm{Na}$ retention. The only hormone capable of causing retention of water, $\mathrm{K}$ and $\mathrm{Na}$ is said to be prolactin (Horrobin, 1973a). In addition, PRL potentiates the renal effects of aldosterone and of anti-diuretic hormone (ADH) (Horrobin, 1973b). Other evidence suggests that PRL may be required for the rise in aldosterone levels following $\mathrm{Na}$ deprivation or furosemide administration (Relkin \& Adachi, 1973; Edwards, Thorner, Miall, Al-Dufaili, Hauber \& Besser, 1975). It is clear that PRL has important interactions with the mineralocorticoids and their effects on the kidney. Prolactin is known to be an important osmoregulatory hormone in several lower vertebrate species (Nicoll \& Bern, 1972) and it has been proposed recently to have an antidiuretic action in man (Carey \& Johanson, 1976). Human PRL secretion has further been shown to respond to induced changes in serum osmolality (Buckman \& Peake, 1973).

Horrobin's group has shown that lithium can antagonize the renal actions of aldosterone and antidiuretic hormone (ADH) in rats, and that the addition of ovine PRL then overcomes this effect of lithium (Mtabaji, Manku \& Horrobin, 1975). A similar interaction between lithium and PRL has been shown in the responses of vascular tissue to norepinephrine (Horrobin et al., 1976). The interactions of lithium with the renal effects of PRL in man have not been studied directly.

2. Many of the treatments proposed for the premenstrual syndrome may antagonize either the secretion of PRL or its effects. The case of bromocriptine was discussed above. The clinical trials with lithium were reviewed in the previous paper and the interactions 
between lithium and PRL were discussed above. There is some evidence that lithium blocks the tissue effects of PRL. On the other hand, there is little evidence that lithium can act like bromocriptine to block the release of PRL (Epstein, Sagel, Zabow, Pimstone \& Vinik, 1975; Smythe, Brandstater \& Lazarus, 1975; Meltzer \& Fang, 1976). It is also possible that lithium could antagonize premenstrual fluid and electrolyte retention by virtue of its diuretic and anti-ADH actions (Baer, 1973). Diuretic agents may be helpful for similar reasons, as may the aldosterone antagonist, spironolactone. The failure of these latter two treatments to be consistently useful, however, suggests that it is not the water and electrolyte retention per se which causes the premenstrual symptoms, but rather a CNS action of the elevated prolactin levels. Horrobin (1973c) has commented on the possibility that furosemide blocks the renal actions of PRL.

Pyridoxine is a relative newcomer in the treatment of premenstrual syndromes and was believed to be effective in at least some women by an effect on tryptophan metabolism (Baumblatt \& Winston, 1970; Stokes \& Mendels, 1972). Most of these reports were anecdotal but some women did appear to benefit from pyridoxine treatment in a dramatic fashion. It is possible that, in these subjects, pyridoxine caused suppression of PRL secretion. Recent evidence indicates clearly that pyridoxine does have this effect when given in large doses to human subjects (Delitala, Masala, Alagna \& DeVilla, 1976).

It is noteworthy that, of all the drugs which have been recommended at one time or another for the treatment of premenstrual dysphoria, phenothiazines are never mentioned in the literature. If there is any basis to the postulated role of PRL in the premenstrual syndromes, then one would expect phenothiazines to worsen the symptoms, by virtue of their elevation of serum PRL levels (Meltzer \& Fang, 1976).

3. Other indirect evidence. Another indirect support for a proposed role of PRL in premenstrual dysphoria comes from a comparison of the endocrine changes which occur premenstrually and in the post-partum period. At the time when the "post-partum blues" occur (typically about the third day after delivery) (Yalom, Lunde, Moos \& Hamburg, 1968), PRL levels are very high, while progesterone and estrogen levels have declined precipitously (Yuen, Keye \& Jaffe, 1973; Jaffe, Yuen, Keye \& Midgley, 1973). This is similar to the pattern seen in the premenstruum. This comparison suggests that high levels of PRL may have behavioral effects in humans, which can be antagonized by estrogens and/or progesterone. Anecdotal support for this behavioral effect of PRL comes from Horrobin (1973a) who describes his reaction to a prolactin injection thus: "The first time I injected prolactin into myself, my wife accused me of being lethargic and irritable, i.e. 'premenstrual'; this first aroused my interest in the syndrome." At that time Horrobin outlined the evidence for a role of PRL in the premenstrual syndromes, and he correctly predicted that bromocriptine would "produce a striking improvement in women with the syndrome." One other piece of anecdotal evidence comes from McNeilly (1973), who reported that women with galactorrhoea and hyperprolactinaemia who were treated with bromocriptine "feel very much better in themselves" while receiving the drug. One further line of indirect evidence is that a strong sensation of thirst is frequently noted in the premenstrual syndromes. Injection of prolactin into humans consistently provokes the sensation of thirst (Horrobin, 1973a; Greenwood, 1973). 


\section{RELATION OF PROLACTIN TO OVARIAN HORMONES AND DYSPHORIA}

Most of the original theories about the premenstrual syndromes focused upon changes in ovarian estrogen or progesterone secretion. At various times it has been suggested that the premenstrual syndrome is caused either by (1) a relative lack of progesterone ("progesterone withdrawal") or (2) a relative lack of estrogen ("estrogen withdrawal"). Laboratory evidence for both of these patterns has been reported (Smith, 1975).

A careful reading of these reports suggests that the confusion and disagreement between these two schools of thought may result from variations in the definition of "premenstrual depression" by different investigators. For example, Dalton (1971), who emphasizes the progesterone deficiency idea, and who claims good results in many cases with progesterone treatment, appears to be describing mostly a syndrome of premenstrual irritability and hostility, rather than depression as such. Similarly, Backstrom \& Carstensen (1974) presented impressive evidence for low progesterone levels in women with "premenstrual anxiety." Cullberg (1972) also concluded that some cases of "premenstrual irritability" were due to estrogen dominance (i.e. a relative lack of progesterone).

On the other hand, Smith and his associates, who carefully selected a group of women with "premenstrual depression, as opposed to irritability, edema or anxiety" found minimal differences in plasma progesterone levels, and no improvement with progesterone injections (Smith, 1975). Similarly, Abraham makes a careful distinction between premenstrual depression and premenstrual hostility-irritability. The depressed women have low plasma estrogens in the luteal phase, resulting in a high progesterone/estrogen ratio. These women respond well to treatment with estrogens. The irritable-hostile women, on the other hand, have low plasma progesterone, as in the report by Backstrom \& Carstensen (1974), and these women respond well to progesterone. Further, the irritable women do poorly with, or are made worse by treatment with estrogens. They also have especially high plasma corticosterone/cortisol ratios in the luteal phase (Schwartz \& Abraham, 1975; Guy E. Abraham, personal written and oral communications, 1976).

These recent findings, in combination with the many early speculations, confirm that the ovarian hormones $d o$ have a role in the production of premenstrual dysphoria. With better differentiation between the depressed group on the one hand and the irritable-anxioushostile group on the other hand, the following scheme suggests itself: Premenstrual depression may result from high levels of prolactin, in conjunction with low levels of estrogen, or relative progesterone dominance. Premenstrual irritability-hostility may result from high levels of prolactin in association with low levels of progesterone. In other words, it may be the interaction of the ovarian hormone changes with elevated prolactin levels which causes the two major types of premenstrual dysphoria. In his comprehensive review of the widespread physiological roles of prolactin Nicoll (1974) emphasized this important aspect of prolactin's actions. He summarized the evidence by stating that PRL has a major role "of modifying the responsiveness of various organs to the influence of other hormones-a broad spectrum conditioner of the hormonal sensitivity of a wide variety of vertebrate organs." These conclusions of Nicoll are consistent with the interactions we are proposing between PRL and the ovarian hormones in the production of premenstrual symptoms. 


\section{RELATION TO OTHER CLINICAL STATES}

An extension of these proposed endocrine-affective relationships may be added by reference to several other clinical phenomena, which have until now been difficult to fit into a coherent framework.

1. Mid-cycle mood elevations. Since the early reports of Benedek \& Rubenstein (1939) it has been known that women at the time of ovulation tend to be happy, alert, and outerdirected, with a peak in ego integration coinciding with the estrogen peaks. In the early luteal phase the features of passivity, narcissism and inner-directedness appear, while in the late luteal phase they reported finding their subjects aggressive, tense and anxious. These descriptions obtained from psychoanalytic material have been confirmed by Bardwick and her associates who studied spontaneous verbal output by the Gottschalk technique (Bardwick, 1976). During this mid-cycle phase plasma estrogen and prolactin levels peak concurrently, as described earlier. These findings tend to suggest that high PRL levels in association with high estrogen levels result in positive rather than negative affective change.

2. Mood elevations in mid- to late pregnancy. Elation during late pregnancy is a common occurrence. Dalton (1971) found that it was present in $64 \%$ of women with puerperal depression, compared with only $26 \%$ of normal women. Patients who experienced the sequence of euphoria in pregnancy followed by post-partum depression described their pregnant state in such terms as "blissful", "never so well in my life", "walked miles with ease" and "boundless energy". Once again, during late pregnancy PRL levels are very high, together with very high estrogen and progesterone levels.

Thus, from these two examples, one might speculate that high levels of both prolactin and estrogen result in positive or euphoric affective change.

3. Post-partum depression. The endocrine changes which occur after delivery are similar to those occurring premenstrually, and the absolute magnitude of hormonal changes is greatly exaggerated. When the post-partum blues occur (usually during the first week after childbirth), the PRL levels are still well above normal values, while the levels of progesterone and estrogen have dropped precipitously (Yuen et al., 1973; Jaffe et al., 1973). Post-partum mood change frequently occurs in women who also experience premenstrual dysphoria and mood elevations during pregnancy (Dalton, 1971).

4. Depression or irritability in post-menopausal women. There have been a number of reports that monthly mood swings occur in some women following their menopause, or after ovariectomy (Smith, 1975). Other women experience more pervasive anxiety and irritability during the menopause. At this time both estrogen and progesterone levels are much reduced (Abraham \& Maroulis, 1975), while circulating prolactin levels are still at pre-menopausal levels and continue to show wide circadian fluctuations (Rozencweig, Heuson, Bila, L'Hermite \& Robyn, 1973; Robyn, Delvoye, Nokin, Vekemans, Badawi, Perez-Lopez \& L'Hermite, 1973). The use of replacement estrogen treatment to control menopausal dysphoric symptoms is well known (Greenblatt, 1965), but there are few well controlled clinical studies in this area (Rose, 1972). It is conceivable that estrogens relieve the symptoms of some depressed post-menopausal women, while progesterone replacement might be more appropriate for those with irritability and anxiety. The prolactin concentrations of post-menopausal women with and without dysphoric symptoms have yet to be studied. 
Winokur \& Cadoret (1975) have noted that episodes of primary affective disorder are not much more frequent at the menopause than at other age periods. This finding is reminiscent of Protheroe's work which indicated that serious post-partum depressions occurred in women with family loadings for affective disorder that were similar to those of women with non-puerperal depression (Protheroe, 1969). Both of these examples suggest that the hormonal changes at the puerperium or the menopause may be only one of a number of possible "triggers" for primary affective disorder in women with the requisite genetic loading. Nevertheless, they are identifiable events, subject to relatively easy experimental manipulation, which could enable us to understand their mechanism.

We are not suggesting that there is a simple relationship between prolactin levels and affective change in women. We are in agreement with Smith (1975) who emphasized that the behavioral changes observed clinically are influenced by additional factors, such as heredity, previous personality, and individual susceptibility to hormonal changes in the central nervous system. We nevertheless believe that some of the clinical examples mentioned earlier would be consistent with the suggestion that a dysphoric depressed mood may occur when high PRL levels are associated with low estrogen levels, whereas a dysphoric anxious or irritable mood may occur when high PRL levels are associated with low progesterone (Table I). Direct clinical testing of these ideas should be possible.

TABLE I. SUGgested INTERACTIONS OF PROLACTIN, ESTROGEN AND PROGESTERONE IN RELATION TO AFFECTIVE CHANGE

\begin{tabular}{llll}
\hline & Prolactin & Estrogen & Progesterone \\
\hline $\begin{array}{l}\text { Premenstrual depression } \\
\begin{array}{l}\text { Premenstrual anxiety- } \\
\text { irritability-hostility }\end{array}\end{array}$ High & Low & Normal \\
$\begin{array}{l}\text { Mid-cycle mood elevation } \\
\text { Late pregnancy }\end{array}$ & High & Normal & Low \\
mood elevation & High & Low \\
$\begin{array}{l}\text { Post-partum depression } \\
\text { Menopausal dysphoria }\end{array}$ & High & High & High \\
& High(?) & Low & Low \\
\hline
\end{tabular}

\section{BEHAVIORAL EFFECTS OF PROLACTIN}

In keeping with the interactive roles that PRL is believed to have with other hormones, it seems that prolactin does not have major behavioral effects of its own. For example, patients with prolactin-secreting pituitary tumors, with idiopathic galactorrhoea and hyperprolactinemia, and patients with isolated prolactin deficiency are not reported to show prominent behavioral disturbances (Gates, Friesen \& Samaan, 1973; Rolland, Schellekens \& Leguin, 1974; Turkington, 1972). This is quite dissimilar from the situation in diseases of the pituitary-adrenal cortical system (Carroll, 1977).

Some brief anecdotal reports have appeared that ovine prolactin injections can cause thirst, lethargy and irritability in humans (Greenwood, 1973; Horrobin, 1973a). McNeilly (1973) also reported that women with galactorrhoea and hyperprolactinemia "feel very much better in themselves" when PRL secretion is suppressed by bromocriptine. Despite 
these few reports, the paucity of observed clinical change in disorders involving PRL is remarkable.

Behavioral effects of PRL in animals are well known and have been reviewed by Nicoll (1974). The effects described are chiefly parental and nesting behavior in teleost fishes, birds and mammals, together with migratory behavior in some species. There is also evidence that PRL may cause some of its behavioral effects through a direct action on the brain.

One obvious area for future study in animals and humans will be the interactions of prolactin with the behavioral effects of adrenocortical and ovarian hormones. Prolactin is an unusual hormone, with over 85 reported actions in vertebrates. Nicoll $(1973,1974)$ has reviewed the animal studies which indicate that "synergisms between (or among) prolactin and steroid hormones (gonadal and adrenal cortical) are prominent features of many of the physiological processes that are influenced (or regulated) by prolactin." In particular, there is much evidence that the temporal interactions of prolactin and ovarian or adrenal hormones are critical in determining the effect of PRL. Nicoll (1973) goes on to emphasize that "temporal interactions among hormones should be given prime consideration in future analyses of normal endocrine physiology and hormone-related pathologies." It is likely that there exist functional disorders related not so much to absolute hormone deficiency or excess, but rather to improper phasing among interacting hormones.

This concept has been well established for some of the tissue effects of prolactin. It is a somewhat new concept for behavioral endocrine research but its potential importance can hardly be overstated, particularly with respect to the periodic disorders (manic-depressive illness and periodic psychosis). The menstrual cycle provides an excellent model for the initial experimental study of this concept in human behavioral pathology.

\section{REFERENCES}

Abraham, G. E. \& Maroulis G. B. (1975) Effects of exogenous estrogen on serum pregnenolone, cortisol and androgens in postmenopausal women. Obstet Gynec. 45, 271-274.

Backstrom, T. \& CARSTENSEN, H. (1974) Estrogen and progesterone in plasma in relation to premenstrual tension. J. Steroid Biochem. 5, 257-260.

BAER, L. (1973) Pharmacology-lithium absorption, distribution, renal handling, and effect on body electrolytes. In Lithium, S. Gershon \& B. Shopsin (Eds.) pp. 33-49. Plenum Press, New York.

BARDWICK, J. M. (1976) Psychological correlates of the menstrual cycle and oral contraceptive medication. In Hormones, Behavior and Psychopathology, E. J. Sachar (Ed.) pp. 95-103. Raven Press, New York.

Baumblatt, M. J. \& Winston, F. (1970) Pyridoxine and the pill. Lancet $i, 833$.

BenedeK, T. \& RUBENSTEIN, B. (1939) The correlations between ovarian activity and psychodynamic processes. I. The ovulation phase. II. The menstrual phase. Psychosom. Med. 1, 245-270, 461-485.

Benedek-Jaszmann, L. J. \& Hearn-Sturtevant, M. D. (1976) Premenstrual tension and functional infertility. Lancet 1, 1095-1098.

Buckman, M. T. \& Peake, G. T. (1973) Osmolar control of prolactin secretion in man. Science 181, $755-757$.

Calne, D. B., Teychenne, P. F., Claverla, L.E., Eastman, R., Greenacre, J. K. \& Petrie, A. (1974) Bromocriptine in Parkinsonism. Br. med.J. 4, 442-444.

Carey, R. M. \& Johanson, A. J. (1976) Prolactin induced antidiuresis in man. The Endocrine Society (USA), Annual Meeting, Abstract No. 216.

CARROLL, B. J. (1977) Psychiatric disorders and steroids. In Neuroregulators and Hypotheses of Psychiatric Disorders, E. Usdin \& J. Barchas (Eds.) pp. 276-282. Raven Press, New York.

Chase, T. N. \& Shoulson, I. (1975) Dopaminergic mechanisms in patients with extrapyramidal disease. In Advances in Neurology, D. B. Calne \& A. Barbeau (Eds.) Vol. 9, pp. 359-366. Raven Press, New York. 
Cooke, I., Foley, M., Lenton, E., Preston, E., Millar, O., Jenkins, A., Obiekwe, B., McNeilly, A., Parsons, J. \& KenNedy, G. (1976) The treatment of puerperal lactation with bromocriptine. Postgrad. Med.J. 52 (Suppl. 1) 75-80.

Cullberg, J. (1972) Mood changes and menstrual symptoms with different gestagen/estrogen combinations. Acta psychiat, neurol. scand. suppl. 236, 1-84.

Dalton, K. (1971) Prospective study into puerperal depression. Br. J. Psychiat. 118, 689-692.

Delitala, G., Masala, A., Alagna, S. \& DeVilla, L. (1976) Effect of pyridoxine on human hypophyseal trophic hormone release: a possible stimulation of hypothalamic dopaminergic pathway. $J$. clin. Endocr. Metab. 42, 603-606.

DelPozo, E. (1973) In Human Prolactin, J. L. Pasteels \& C. Robyn (Eds.) pp. 218-220. Excerpta Medica, International Congress Series, No. 308, Amsterdam.

Edwards, C. R. W., Thorner, M. O., Miall, P. A., Al-Dufalli, E. A. S., Hauber, J. P. \& Besser, G. M. (1975) Inhibition of the plasma-aldosterone response to furosemide by bromocriptine. Lancet 2, 903-905.

Epstein, S., Sagel, J., Zabow, T., Pimstone, B. \& Vinik, A. (1975) The effect of prolonged lithium carbonate administration on the thyrotrophin and prolactin response to thyrotrophin releasing hormone S. Afr. med.J. 49, 1977-1979.

Franchimont, P., Dourcy, C., Legros, J. J., Reuter, A., Vrindts-Gevaert, Y., Van Cauwenberge, J. R. \& GASPARD, U. (1976) Prolactin levels during the menstrual cycle. Clin. Endoc. 5, 643-650.

Fuxe, K., Agnati, L. F., Hokfelt, T., Jonsson, G., Lidbrink, P., LJungdahl, A., Lofstrom, A. \& UNGERSTEDT, U. (1975) The effect of dopamine receptor stimulating and blocking agents on the activity of supersensitive dopamine receptors and on the amine turnover in various dopamine nerve terminal systems in the rat brain. J. Pharmac. (Paris) 6, 117-129.

GATES, R. B., FrIESEN, H. \& SAMAAN, N. A. (1973) Inappropriate lactation and amenorrhoea: pathological and diagnostic considerations. Acta Endocrinol. $(K b h)$ 72, 101-114.

GreENBlatT, R. B. (1965) Estrogen therapy for post-menopausal females. New Engl. J. Med. 272, 305-308.

Greenwood, F. C. (1973) In Human Prolactin, J. L. Pasteels \& C. Robyn (Eds.) p. 325. Excerpta Medica, International Congress Series, No. 308, Amsterdam.

Halbreich, U., Assael, M., Ben-David, M. \& Borstein, R. (1976) Serum prolactin in women with premenstrual syndrome. Lancet $\mathbf{i i}, 654-656$.

Horrobin, D. F. (1973a) Premenstrual syndrome and pregnancy toxemia. In Prolactin: Physiology and Clinical Significance, pp. 115-120. Medical and Technical, Lancaster, United Kingdom.

Horrobin, D. F. (1973b) Prolactin and fluid and electrolyte balance and the cardiovascular system. In Prolactin: Physiology and Clinical Significance, pp. 72-79, Medical and Technical, Lancaster, United Kingdom.

Horrobin, D. F. (1973c) Disorders of fluid and electrolyte balance. In Prolactin: Physiology and Clinical Significance, pp. 128-129. Medical and Technical, Lancaster, United Kingdom.

Horrobin, D. F., Mtabaj, J. P., Karmali, R. A., Manku, M. S. \& Nassar, B. A. (1976) Prolactin and mental illness. Post-grad. med.J. 52 (Suppl. 3): 79-85.

ISRAEL, S. L. (1967) Menstrual Distress and Sterility, 5th ed., Hoeber, New York.

JAfFe, R. B., Yuen, B. H., KeYe, W. R., JR. \& MidGlex, A. R. (1973) Physiologic and pathologic profiles of circulating human prolactin. Am.J. Obstet. Gynec. 117, 757-773.

Lemberger, L., Crabtree, R., Clemens, J., Dyke, R. \& Woodburn, R. (1974) The inhibitory effect of an ergoline derivative (Lergotrile, Comp. 83636) on prolactin secretion in man. J. clin. Endocr. Metab. 39, 579-584.

McNeilly, A. S. (1973) In Human Prolactin, J. L. Pasteels \& C. Robyn (Eds.), p. 325. Excerpta Medica, International Congress Series, No. 308, Amsterdam.

Malarkey, W. B., Jacobs, L. S. \& DaughadaY, W. H. (1971) Levodopa suppression of prolactin in nonpuerperal galactorrhea. New Engl.J. Med. 285, 1160-1163.

Martin, J. B., Lal, S., Tolis, G. \& Friesen, H. G. (1974) Inhibition by apomorphine of prolactin secretion in patients with elevated serum prolactin. J. clin. Endocr. Metab. 39, 180-182.

Massara, F., Camanni, F., Belforte, L. \& Molinatti, G. (1976) Dopamine induced inhibition of prolactin and growth hormone secretion in acromegaly. Lancet (letter) $i, 485$.

Meltzer, H. Y. \& FANG, V. S. (1976) Serum prolactin levels in schizophrenia-effect of antipsychotic drugs: a preliminary report. In Hormones, Behavior and Psychopathology, E. J. Sachar (Ed.) pp. 177-191. Raven Press, New York.

Mtabaji, J. P., Manku, M. S. \& Horrobin, D. F. (1975) Effects of prolactin, antidiuretic hormone and aldosterone in the polyuric syndrome produced by lithium treatment in male rats. $J$. Endocr. 67, 57P. 
Nicoll, C. S. (1973) "Spinoff" from comparative studies on prolactin physiology of significance to the clinical endocrinologist. In Human Prolactin, J. L. Pasteels \& C. Robyn (Eds.), pp. 119-148. Excerpta Medica, International Congress Series, No. 308, Amsterdam.

Nicoll, C. S. (1974) Physiological actions of prolactin. In Handbook of Physiology, pp. 253-292. American Physiological Society, Washington, D.C.

Nicoll, C. S. \& BerN, H. A. (1972) On the actions of prolactin among the vertebrates: is there a common denominator? In Lactogenic Hormones, G. E. W. Wolstenholme \& J. Knight (Eds.) pp. 299-317. Churchill and Livingston, England.

Protheroe, C. (1969) Puerperal psychoses: a long-term study (1927-1961). Br. J. Psychiat. 115, 9-30.

RELKIN, R. \& ADACHI, M. (1973) Effects of sodium deprivation on pituitary and plasma prolactin, growth hormone and thyrotropin levels in the rat. Neuroendocrinology 11, 240-247.

Robyn, C., Delvoye, P., Nokin, J., Vekemans, M., Badawi, M., Perez-Lopez, F. R. \& L'Hermite, M. (1973) Prolactin and human reproduction. In Human Prolactin, J. L. Pasteels \& C. Robyn (Eds.) pp. 167-188, Excerpta Medica, International Congress Series, No. 308, Amsterdam.

Rolland, R., Schellekens, L. A. \& Lequin, R. M. (1974) Successful treatment of galactorrhoea and amenorrhoea and subsequent restoration of ovarian function by a new ergot alkaloid 2 brom-a-ergocryptine. Clin. Endocr. 3, 155-165.

Rose, R. M. (1972) The psychological effects of androgens and estrogens: a review. In Psychiatric Complications of Medical Drugs, R. L. Shader (Ed.) pp. 251-293. Raven Press, New York.

Rozencweig, M., Heuson, J. C., Bila, S., L'Hermite, M. \& Robyn, C. (1973), Effects of 2-Br-alpha-ergocryptine, L-dopa and cyclic imides on serum prolactin in postmenopausal women. Europ. J. Cancer 9, 657664.

Schwartz, U. D. \& Abraham, G. E. (1975) Corticosterone and aldosterone levels during the menstrual cycle. Obstet. Gynec. 45, 339-342.

Shane, J. M. \& Naftolin, F. (1974) Effect of ergonovine maleate on puerperal prolactin. Am. J. Obstet. Gynec. 120, 129-131.

Smith, S. L. (1975) Mood and the menstrual cycle. In Topics in Psychoendocrinology, E. J. Sachar (Ed.) pp. 19-58. Grune \& Stratton, New York.

Smythe, G. A., Brandstater, J. F. \& Lazarus, L. (1975) The acute effects of lithium on central dopamine and serotonin activity as reflected by inhibition of prolactin and growth hormone secretion in the rat. Proc. Endocrine Soc. of Australia, 18th Annual Meeting, Sydney, Australia. Abstract No. 50.

STEINER, M. \& CARRoll, B. J. (1977) The psychobiology of premenstrual dysphoria: review of theories and treatments. Psychoneuroendocrinology 2: 321-335.

Stokes, J. \& MENDELS, J. (1972) Pyridoxine and premenstrual tension. Lancet 1, 1177-1178.

Thorner, M. O., McNeilly, A. S., HaGan, C. \& Besser, G. M. (1974) Long-term treatment of galactorrhoea and hypogonadism with bromocriptine. Br. med.J. 2, 419-421.

Turkington, R. W. (1972) Phenothiazine stimulation test for prolactin reserve: the syndrome of isolated prolactin deficiency. J. clin Endocr. Metab. 34, 247-249.

Vekemans, M., Delvoye, P., L'Hermite, M. \& Robyn, C. (1977) Serum prolactin levels during the menstrual cycle. J. clin. Endocr. Metab. 44, 989-993.

WinokuR, G. \& CADORET, R. (1975) The irrelevance of the menopause to depressive disease. In Topics in Psychoendocrinology, E. J. Sachar (Ed.) pp. 59-66. Grune \& Stratton, New York.

Yalom, I. D., Lunde, D. T., Moos, R. H. \& HamburG, D. A. (1968) "Postpartum blues" syndrome. A description and related variables. Archs gen. Psychiat. 18, 16-27.

YUEN, B. H., KEYE, W. R., JR., \& JAFFE, R. B. (1973) Human prolactin: secretion, regulation and pathophysiology. Obstet. Gynec. Survey 28, 527-541. 